\title{
The Self-Hollowing Problem of the Radical Sceptical Paradox
}

\author{
Changsheng Lai ${ }^{1}$ (1)
}

Received: 12 October 2017 / Accepted: 15 October 2018 / Published online: 1 November 2018

(c) The Author(s) 2018

\begin{abstract}
The purpose of this paper is to provide a new solution to the radical sceptical paradox. A sceptical paradox purports to indicate the inconsistency within our fundamental epistemological commitments that are all seemingly plausible. Typically, sceptics employ an intuitively appealing epistemic principle (e.g., the closure principle, the underdetermination principle) to derive the sceptical conclusion. This paper will reveal a dilemma intrinsic to the sceptical paradox, which I refer to as the selfhollowing problem of radical scepticism. That is, on the one hand, if the sceptical conclusion turns out to be true, then the epistemic principle employed by sceptics would lose its foundation of plausibility; on the other hand, if the sceptical conclusion does not follow, then the sceptical problem would not arise. In either case, the so-called sceptical paradox cannot be a genuine paradox. This new solution has three theoretical merits: it is undercutting, less theory-laden, and widely applicable.
\end{abstract}

It has been widely accepted that radical scepticism presents us with a sceptical paradox, ${ }^{1}$ which purports to indicate the inconsistency within our fundamental epistemological commitments. Typically, a sceptical paradox utilises an intuitively appealing epistemic principle (e.g., the closure principle) to derive the sceptical conclusion. This paper will provide a new solution to the sceptical problem by revealing the self-undermining nature of sceptical paradoxes. A dilemma intrinsic to scepticism would be shown. That is, a genuine sceptical paradox needs the epistemic principle it employs to be well-grounded; however, the well-grounded-ness of the epistemic principle will hinder the sceptical conclusion from being coherently derived, since the plausibility of the relevant epistemic principle is rooted in our widespread

\footnotetext{
1 See Pritchard (2009, 2015), Wright (2008), Wong (2005), Byrne (2004), Engel (2004) and Stroud (1984); etc.

Changsheng Lai

s1362907@sms.ed.ac.uk

1 School of Philosophy Psychology and Language Sciences, The University of Edinburgh, Dugald Stewart Building (Room 2.17), 3 Charles St Ln, Edinburgh EH8 9AD, Scotland, UK
} 
everyday knowledge. Call this dilemma the self-hollowing problem of scepticism, which will be the key to solving the sceptical paradox.

This paper will proceed as follows: starting with the closure-based radical scepticism, Sect. 1 will discuss the paradoxical nature of scepticism. By analysing mainstream anti-sceptical proposals in the literature, Sect. 2 will list desiderata for an ideal solution to the sceptical paradox. In Sect. 3, I will articulate the notion "selfhollowing" and reveal the self-hollowing problem of scepticism. Section 4 will address possible objections. Finally, Sect. 5 will summarise the new solution's theoretical merits in terms of the desiderata given in Sect. 2.

\section{Sceptical Paradox}

\subsection{Background}

Radical scepticism argues that we do not possess any everyday knowledge that we ordinarily claim to possess. A paradox reading of radical scepticism has gained wide acceptance (see Pritchard 2009, 2015; Wright 2008; Byrne 2004; etc.), which interprets scepticism as presenting a paradox to be solved. According to an oftenquoted definition of "paradox" given by Mark Sainsbury, a paradox consists of "an apparently unacceptable conclusion derived by apparently acceptable reasoning from apparently acceptable premises" $(2009$, p. 1). That is to say, a genuine paradox is constituted by a set of plausible while inconsistent propositions. Accordingly, a sceptical paradox aims to reveal the inconsistency within our seemingly plausible fundamental epistemological commitments. Take the most-discussed closure-based sceptical paradox for example:

[Closure-Based Radical Sceptical Paradox]

(PC1) If one knows that $p$ and that $p$ entails $q$, then one knows that $q$.

(PC2) I do not know that I am not a brain-in-a-vat (hereafter, BIV).

(PC3) I have widespread everyday knowledge.

PC1 is the widely-accepted closure principle. ${ }^{2}$ Despite disputes around the optimal formulation of closure, it is much less contentious that closure is generally (if not universally) applicable in our daily epistemic practice. For example, I know that the shop will be closed on Sunday and that today is Sunday, hence I know that the shop is closed today. In addition, closure is also essential for extending our knowledge by deduction from what we already know. ${ }^{3}$ Competent deduction is taken to be a paradigmatic instance of cognitive actions generating knowledge. Its significance

\footnotetext{
${ }^{2}$ For the sake of simplicity, I will focus on this simple form of closure, which is referred to as "known entailment closure" (see Bernecker 2012, p. 368). Of course, there is more than one formulation of the closure principle (see Hawthorne 2004; Klein 2004; Dretske 2005; Kvanvig 2006; Pritchard 2015). Focusing on the known entailment closure will be enough for the purpose of this paper. However, it can also be replaced by other forms of closure without affecting my main argument.

3 This idea is typically reflected by a sophisticated formulation of closure, i.e., the competent deduction closure: if a subject $\mathrm{S}$ knows that $p$ and comes to believe that $q$ by completely deducing $q$ from $p$, then $\mathrm{S}$ knows that $q$.
} 
is embodied in the closure principle. Given the remarkable epistemological importance of closure, it is ordinarily deemed extremely irrational to abandon closure (see Pritchard 2005b, 2015; Ashton 2015). In light of this, despite a few voices arguing that closure is substantially irrelevant to scepticism (e.g., Schönbaumsfeld 2016), ${ }^{4}$ closure-based scepticism is of interest to the majority of epistemologists due to the plausibility and importance of closure. Schönbaumsfeld also recognises closurebased scepticism as "the most popular way of motivating radical scepticism in the contemporary literature" (2016, p. 7). That is why I take this form of scepticism as an ideal example to start with. ${ }^{5}$

PC2 involves a prima facie appealing sceptical hypothesis. The sceptical scenario stipulates that a BIV's illusory perceptual experiences are introspectively indistinguishable from those of her non-envatted duplicate. Moreover, if one were a BIV, one would still believe the opposite. Thus, it seems that one cannot tell whether s/he is a BIV.

The truth of PC3 is ordinarily taken for granted. The denial of PC3 simply implies one's epistemic catastrophe. Given PC1 and PC2, if I possess everyday knowledge, then I also know that I am not a BIV. However, the consequent of this conditional is rejected by PC2, and thus by modus tollens, I do not have everyday knowledge. Therefore, the three intuitively appealing propositions, viz, PC1, PC2, and PC3, cannot obtain simultaneously. Being committed to all of the three propositions will give rise to inconsistency, whilst rejecting any one of them will lead to an unwanted epistemic impact. The problem of radical scepticism is thus paradoxical and thorny.

\subsection{Diagnosis}

An essential feature of the sceptical paradox is that it seems to reveal the intrinsic incoherence within our fundamental epistemological commitments. To achieve this, sceptics resort to an underlying argument to the effect that closure helps to entail the sceptical conclusion:

[Closure-Base Radical Sceptical Argument]

(AC1) If I know everyday propositions and that everyday propositions entail that I am not a BIV, then I know that I am not a BIV. [Closure]

(AC2) I do not know that I am not a BIV. [Sceptical hypothesis]

(AC3) I do not have any everyday knowledge. [Sceptical conclusion]

\footnotetext{
4 Atkins and Nance (2014) and Floridi (2014) have also made similar points.

5 Schönbaumsfeld (2016) argues that what does the real sceptical work is not closure, but the socalled "reason identity thesis" and the background "default view" of perceptual reasons (for a criticism of Schönbaumsfeld's argument, see Baumann 2017). This does not affect my main argument because closure-based scepticism is just a replaceable example for my purpose. In addition, Schönbaumsfeld's sceptical argument also shares the same template that is subject to the self-hollowing problem, as it also employs an epistemic principle (which is embodied by her "reason identity thesis") requiring our perceptual reasons to be different in good and bad cases. We will discuss this template later in Sects. 2 and 5.
} 
The sceptical argument is prima facie valid, and its premises are seemingly wellgrounded. In particular, we have seen that closure is borne out by its broad successful applications in our daily epistemic practices. We feel anxious when encountering the sceptical paradox, because we might be forced to abandon the well-grounded closure principle. Our commitments to the validity of closure are not groundless. Note that not all true conditionals are equally epistemically significant. Some are well-grounded and informative (e.g., "if John owns the gun, then he is the murderer"), while some are ill-grounded and trivial (e.g., "if there is a unicorn, then it is blue-eyed"). The closure principle, qua a conditional, is ordinarily taken to fall into the former category. We find the closure principle well-grounded and informative-it does apparently reveal some instructive information about the nature of knowledge, which can guide us to make knowledge ascriptions or to extend our knowledge. Otherwise, it will be hard to explain why we shall credit closure with the significant epistemic appeal.

With these being said, it can be summarised that the paradoxical nature of closure-based scepticism turns essentially on two impressions of ours:

(I1) The validity of the closure principle is well-grounded.

(I2) The sceptical conclusion is validly deduced.

By claiming the validity of the closure principle to be "well-grounded", I mean that the validity of closure is supported by good evidence or reasons. By claiming the sceptical conclusion to be "validly deduced", I mean two things: first, the sceptical argument has to be logically valid; second, the sceptical conclusion is supposed to be true, as sceptics need all premises of the sceptical argument to be true as well, and a valid deduction is truth-transmitting.

Denying either of the two impressions can disarm the closure-based sceptical paradox. On the one hand, rejecting 12 implies that the sceptical conclusion does not follow, and hence there will be no sceptical paradox. On the other hand, if I1 is rejected, then the plausibility of the sceptical argument is questionable, as the argument contains an ill-grounded (or even groundless) premise. More importantly, a sceptical paradox trading upon a groundless closure principle is just not the epistemologically challenging sceptical paradox that we have in mind. We would not even be interested in the problem of scepticism so constructed. The sceptical paradox is thorny, because it imperils some fundamental epistemological commitments that we deem well-grounded and unabandonable_-including closure. If we do not see the closure principle as well-grounded, then the problem of scepticism would not have arisen. After all, what epistemological loss will it bring on if we abandon a groundless claim that invites scepticism? Why shall we even feel anxious when required to relinquish it to save our everyday knowledge?

Hence, it is crucial for the sceptical paradox that both I1 and I2 obtain. Correspondingly, there are at least three roads that anti-scepticism can take: rejecting I1, rejecting I2, or, indicating that I1 and I2 are incompatible. Traditionally, most anti-sceptical proposals are inclined to take the first two roads. For instance, Nozick (1981) and Dretske (1970) famously argue against the closure principle, which can be regarded as a typical way to reject I1. In contrast, Pritchard (2015) strives to disprove $\mathrm{I} 2$ by arguing that the closure-based inference cannot be applied to "hinge 
commitments" and thus the sceptical conclusion does not follow. Epistemological contextualism can also be seen as attempting to disprove I 2 in terms of the contextualist account of knowledge-given that "knows" is a context-sensitive term, even if we cannot know that we are not BIVs in a sceptical context, it does not mean that the sceptical conclusion follows in a non-sceptical context.

Most existing anti-sceptical proposals are aimed at rejecting either I1 or I 2 respectively. However, the compatibility of I1 and I2 went unchallenged in vast swathes of the contemporary literature. ${ }^{6}$ It is almost a consensual view that the two claims are reconcilable. That is understandable, since it seems that it is exactly the wellgrounded closure principle that helps to entail the sceptical conclusion-I1 appears to be not only compatible with, but also supportive of I2. This paper argues against this consensual view and aims to usher "a third road" toward resolving the sceptical paradox by revealing the contradiction between I1 and I2. I will explain why this third road is preferable later on. Before turning to my own solution, it is helpful to decide on the desiderata for an ideal anti-sceptical solution. The advantages of my solution can thereby be shown in terms of those desiderata.

\section{Desiderata}

According to Pritchard $(2015,2016)$, there are two types of anti-sceptical strategies, namely, the overriding strategy and the undercutting strategy. Simply put, the most essential distinction between the two types of strategies lies in whether to admit the alleged sceptical paradox as a genuine paradox. Overriding anti-sceptical strategies admit it, while undercutting ones do not. Typically, an overriding anti-sceptical proposal will reject one of the three propositions constituting the sceptical paradox. Pritchard (2016) presents Sosa's neo-Moorean solution (see Sosa 1999) as a paradigmatic instance of overriding strategies, which takes an epistemic externalist line to reject PC2 ("I do not know that I am not a BIV"). ${ }^{7}$ Also, an overriding proposal can come in the form of epistemological revisionism, which bites the bullet and contends that the sceptical paradox is unsolvable ${ }^{8}$ and our epistemic concepts are incoherent indeed (e.g., see Schiffer 1996, 2004). Overriding strategies always come along with the pain of revising our epistemic concepts fundamentally. On the contrary, undercutting anti-sceptical strategies attempt to show the alleged incoherence is just illusory and thus the so-called sceptical paradox is not genuine. For example,

\footnotetext{
${ }^{6}$ Of anti-sceptical proposals on offer in the current literature, Coliva (2015) strikes me as a borderline exception. Coliva develops a constitutivism of epistemic rationality, which argues that our epistemic rationality is shared by both sceptics and anti-sceptics, since it is rooted in our shared epistemic practices. Sceptics cannot arrive at the sceptical conclusion whilst denying our shared epistemic rationality (see Coliva 2015, ch. 4). However, her criticism targets on Humean scepticism rather than the (Cartesian) radical scepticism that this paper interests in. In addition, Coliva does not unpack her notion of "epistemic rationality" to the effect that it includes the closure principle. Rather, her articulation of epistemic rationality is more focused on hinge commitments.

7 For more detailed discussions of this strategy, see Sosa (1999) and Pritchard (2005a).

${ }^{8}$ It is thus plausible to doubt whether an overriding strategy like this is still "anti-sceptical". One may find the revisionist proposal more like a concessive response, rather than a convincing refutation, to scepticism. This can also explain why the revisionist proposal is unsatisfactory.
} 
Pritchard (2015) proposes to solve sceptical paradoxes by combining hinge epistemology with epistemological disjunctivism. Ashton (2015) advocates an anti-sceptical proposal drawing on Michael Williams's inferential contextualism. They both claim their solutions to be undercutting.

I agree with Pritchard on the point that an undercutting solution is preferable to an overriding one, ceteris paribus. As Pritchard points out:

"[I]f successful they (undercutting strategies) will offer a more powerful philosophical resolution of the sceptical problem as one would not be obliged to revise one's fundamental epistemological commitments after all." (2016, p. 4) 9

Thus, being undercutting rather than overriding should be our first desideratum. Besides, a less theory-laden solution ought to be preferable as well. Various theories of knowledge have been developed in the literature in order to solve the problem of scepticism. Some notable instances include Dretske's anti-sceptical proposal, which is based on his relevant alternative theory (see Dretske 1970, 1981), and subsequent contextualist anti-sceptical proposals relying crucially on contextualist accounts of knowledge (see DeRose 1995, 1999; Goldman 1976; Williams 1996; Cohen 1998; etc.). Likewise, the sensitivity account (Nozick 1981) and safety account (Sosa 1999; Williamson 2000; Pritchard 2007) of knowledge have also motivated numerous anti-sceptical strategies.

I cannot exhaust all relevant instances. ${ }^{10}$ What I would like to emphasise is just that the validity of a theory-laden solution is particularly conditional, since it is premised on its underpinning theory. This could be a noteworthy defect for an antisceptical solution, as any anti-sceptical proposal underpinned by a specific account of knowledge has to defend its underpinning theory before it can be applied to cope with scepticism. Hence, it is highly likely that discommenders of the underpinning theory of knowledge would also reject the theory-laden anti-sceptical proposal. That means a heavier burden of proof.

Moreover, it is unclear whether a theory-laden solution can thoroughly refute scepticism in a non-circular manner. Most epistemological theories that theory-laden anti-sceptical solutions employ aim to analyse the nature of knowledge. Our everyday knowledge is the essential object of study for those epistemological theories. Theory-laden solutions attempt to reject scepticism by telling us what the real nature of our everyday knowledge is, and why scepticism misunderstands that nature. But

\footnotetext{
${ }^{9}$ By combining the Wittgenstein-inspired hinge epistemology and epistemological disjunctivism, Pritchard (2015) attempts to solve the closure-based and the underdetermination-based sceptical paradoxes in an undercutting manner. However, a conclusion of his hinge proposal is that we do not know hinge commitments like "I have hands" as they are just not in the market for knowledge (in fact, it is argued that our hinge commitments are not even beliefs). It is unclear whether this conclusion is so much better than sceptics', and whether this requires us to revise our fundamental epistemological commitments (e.g., our commitment to "I know that I have hands") like overriding strategies suggest. In addition, Ashton (2015) also argues that Pritchard's epistemological disjunctivist solution might take the risk of being overriding rather than undercutting.

${ }^{10}$ For some other representative examples, see Pritchard (2015), which employs hinge epistemology and epistemological disjunctivism; Greco (2002), which resorts to virtue reliabilism; Hetherington (2001), which is based on Hetherington's epistemic gradualism.
} 
what if we do not have everyday knowledge? To be more specific, if a theory of knowledge is at all plausible to us, then it must accord with our understandings of knowledge that we think we possess- that is the foundation of its plausibility. However, what the sceptical paradox imperils is exactly this foundation. Theory-laden anti-sceptical strategies are thus inclined to take what they ought to demonstrate to be their premises. Hence, to avoid begging the question, a freestanding anti-sceptical strategy is more ideal.

The last desideratum that I would like to emphasise is the wide applicability. Besides the closure-based one, there are many other forms of sceptical paradoxes (see Brueckner 1994, 2005; Huemer 2001; Pritchard 2005b; Schaffer 2010; etc.). According to Pritchard (2015), another mainstream form of sceptical paradox is the underdetermination-based sceptical paradox, which can be formulated as follows:

[Underdetermination-Based Radical Sceptical Paradox]:

(PU1) If I lack better rational support which favours my beliefs of everyday propositions over that I am a BIV, then I do not have everyday knowledge. [Underdetermination]

(PU2) I lack better rational support which favours my beliefs of everyday propositions over that I am a BIV.

(PU3) I have widespread everyday knowledge.

Pritchard argues that this form of sceptical paradox, which is based on the underdetermination principle (i.e., "if a subject $\mathrm{S}$ knows that $p$ is incompatible with $q$, and $\mathrm{S}$ lacks a rational reason for preferring $p$ over $q$, then $\mathrm{S}$ lacks knowledge that $p$ "), fundamentally differs from the closure-based one, and thus requires a distinct solution (see Pritchard 2015). Nevertheless, for the sake of simplicity and efficiency, it would be still ideal if we can put forward an anti-sceptical strategy that is applicable to different types of sceptical paradoxes.

In summary, we have three desiderata for a satisfactory solution to the sceptical paradox: (a) being undercutting; (b) being less theory-laden; (c) being widely applicable. In what follows, I will offer a solution that satisfies all of these criteria.

\section{The Self-Hollowing Problem}

\subsection{Preliminaries}

The sceptical paradox consists of three propositions. Each of them has to be plausible from the outset if the sceptical paradox is to be genuinely paradoxical. Ordinarily, a plausible proposition is plausible for some reasons - the plausibility has its rational foundation. Some plausible propositions are based on true and solid rational foundations, so those propositions are well-grounded. In contrast, some propositions' foundations of plausibility turn out to be false or illusory, so they are hollow propositions. Let me define: 
[Hollow Proposition]

A proposition $p$ is hollow, iff, the plausibility of $p$ is based on $a^{11}$ rational foundation $\mathrm{F}$, and $\mathrm{F}$ is illusory or false.

F can be expected to consist of an impression, or an item of putative ${ }^{12}$ fact $/ \mathrm{knowl}$ edge and the like. For example, the plausibility of the statement that "if a swan is healthy, then it can swim" is based on our observations and empirical knowledge of swans. It is premised on the fact that there are healthy swans that can swim. This statement will become hollow if, somehow, it turns out that there has never been any creature called swan. Similarly, the statement "a man who has long arms can swim faster" would become hollow if it turns out that every man is arm-less; the claim "everything made of glass is fragile" would become hollow if it turns out that nothing in the world is made of glass. Likewise, if the plausibility of closure is based on our possession of everyday knowledge, then the closure principle would become hollow once the sceptical conclusion is proven to be true.

An argument is self-hollowing, iff, its conclusion renders its premise(s) hollow. Note that the self-hollowing-ness of an argument is different from the hollowness of a proposition. The former expresses a relationship between an argument's conclusion and premise(s) - if the conclusion is true, then the premise(s) would be hollow. Consider the following arguments:

[Argument One]

Premise 1: If there are no true contradictions, then it is not the case that dialetheism is correct.

Premise 2: Dialetheism is correct.

Conclusion: There are true contradictions.

Dialetheism argues that there are true contradictions, which contradicts the antecedent of premise 1 straightforwardly. Thus, premise 1 is apparently plausible. However, the apparent validity of premise 1 relies on the assumption that there are no true contradictions. Otherwise, it can be the case that the conjunction "there are no true contradictions and dialetheism is correct" is a true contradiction, which will critically undermine the plausibility of premise 1. Argument one is thus self-hollowing in the sense that premise 1 would lose its foundation of plausibility given the conclusion.

\section{[Argument Two]}

Premise 1: If one were a time-traveller, then one would be able to kill her/his grandfather before her/his father was born.

Premise 2: It is impossible for one to kill her/his grandfather before her/his father was born.

Conclusion: It is impossible for one to be a time-traveller.

\footnotetext{
11 The plausibility of a proposition $p$ can be based on many Fs, each can serve as a necessary condition for $p$ 's being appealing.

12 A putative fact is not guaranteed to be factive indeed. When $\mathrm{F}$ is proven to be false, the putative fact or knowledge would turn out be false, and hence, fail to qualify as fact or knowledge.
} 
Premise 1 is plausible as it seems that in a possible world where one is a time-traveller, it is reasonable that one has the ability to murder anyone, including her/his grandfatherjust like in the actual world. The subjunctive conditional expressed by premise 1 is thus seemingly true. However, if the conclusion is true, viz, there is no possible world where one could be a time-traveller, then it would be unclear how we can determine the truth value of premise 1 in a non-trivial manner (still, it can be trivially true), nor why we shall deem premise 1 plausible. In that case, premise 1 would be a hollow conditional as unappealing as "if a tautology is false, then one can kill her/his grandfather before her/his father was born". This indicates the self-hollowing nature of the argument above.

[Argument Three]

Premise 1: It is good to generate a greater overall utility.

Premise 2: Rejecting utilitarianism can generate a greater overall utility.

Conclusion: Utilitarianism should be rejected.

Premise 1's plausibility is based on the impression that utilitarianism is acceptable, as utilitarianism (at least in its simplest form) claims that an action is morally good if it can lead to a greater overall utility. If one endorses that utilitarianism should be rejected, then one would not find premise 1 plausible. Therefore, this argument is also self-hollowing.

In summary, a typical self-hollowing argument will give rise to an intrinsic dilemma: on the one hand, if its conclusion is true, then its premise would lose the foundation of plausibility and thus becomes highly questionable; on the other hand, if its conclusion is false, then the whole argument fails. Call this type of dilemma the self-hollowing problem. Indeed, a self-hollowing argument might still remain valid and even sound, as their premises can be trivially true. However, the intrinsic tension within the logical structure of a self-hollowing argument would severely undermine its plausibility. In light of this, if the sceptical argument is shown to be self-hollowing, then it can hardly be employed to motivate a genuine paradox.

In what follows, I will argue that I1 contradicts I2; hence the sceptical argument is self-hollowing and subject to a fatal dilemma.

\subsection{Dilemma}

According to the brief diagnosis we made at the end of Sect. 1, the problem of scepticism is paradoxical because we are committed to two claims:

(I1) The truth of the closure principle is well-grounded.

(I2) The sceptical conclusion is validly deduced.

Let me further hammer home this point. The success of the sceptical argument is essential for the sceptical paradox, hence I2 cannot contradict the truth/validity of closure. So, can I 2 contradict the well-grounded-ness of closure? That is, can I 2 contradict I1? A closer analysis of how closure gains its plausibility can shed some light on this question.

As previously mentioned, we find closure appealing since it appears to be wellgrounded. It seems to be a widely applicable and verifiable principle, which reveals 
the fact that knowledge is closed under known deduction. The closure principle does not involve an analytic truth in accordance with the definition of "knowledge". Compare closure with the statement below:

(a) If a man is a bachelor, then he is unmarried.

Statement (a) is a paradigmatic analytic truth explaining the definition of a "bachelor". It is true by definition. While the closure principle is not a statement concerning the definition of "knows". Hence the closure principle has a different source of plausibility from that of an analytically true proposition.

Also, closure's plausibility is not based on our empty imaginations of a fictional concept of "knowledge". We do not form our beliefs of closure's validity out of thin air. Consider the following statement:

(b) If a man has wings, then his wings are white-feathered.

Statement (b) is imaginary and ill-grounded in that it cannot be verified or falsified by any fact in the world, given that no human has wings. If (b) is of any plausibility, it is based on our reasonable imagination of "human's wings". Statement (b), qua a conditional, albeit (trivially) true, is hollow. Is the plausibility of closure also based on our imagination of "everyday knowledge"? No. Quite the opposite, we take closure to be verifiable by its widespread successful applications to our everyday knowledge. Our widespread everyday knowledge is the "playground" of closure. Without this "playground", it will be mysterious why we would take closure to be applicable to the domain of everyday knowledge and so appealing. Our commitments to the closure principle are premised on the fact that we think we possess widespread everyday knowledge. To be more specific, we are committed to this claim:

(I1*) The closure principle employed by scepticism is well-grounded in our widespread knowledge.

I1* is a more precise formulation of I1. A paradox has to contain some propositions that we grant to be true. Thus, the mere truth of closure is insufficient for the sceptical paradox to be paradoxical. ${ }^{13}$ Closure has to be appealing and wellgrounded. Given $\mathrm{I}^{*}$, the rational foundation of closure's plausibility lies in our widespread everyday knowledge. If it turns out that we do not have any everyday knowledge, then the closure principle employed by scepticism would become ill-grounded and hollow. Consequently, the alleged sceptical paradox would be disarmed.

Admittedly, the closure principle, qua a conditional, could still remain trivially true if the sceptical conclusion is true. Nevertheless, if the validity of closure is merely based on its triviality, then why is it unabandonable? Why shall we keep regarding the closure principle as appealing if there is no knowledge at all? What unabandonable merits can a principle have, if the principle is completely

\footnotetext{
13 A trivially true proposition cannot suffice to constitute a genuine paradox. Consider an argument as follows: "If pigs have wings, then pigs can fly. Pigs cannot fly. Therefore, pigs have no wings." The first premise is a trivially true proposition, but the whole argument is not paradoxical at all.
} 
inapplicable to what it is supposed to be applied to? Now that its validity cannot be verified or falsified by any item of everyday knowledge, then why cannot we abandon it and adopt its competing claim "if one knows that $p$ and that $p$ entails $q$, then one might not know that $q$ "? The two claims are both trivially true, both unverifiable and unfalsifiable. They are equally (un)appealing. We do not have sufficient reason to favour the trivial closure rather than its competing claim. If the closure principle can be abandoned or replaced easily without any theoretical loss, then why shall we recognise it as our fundamental epistemological commitment? We shall not. As a result, the alleged sceptical paradox would fail to reveal the alleged inconsistency within our fundamental epistemological commitments as it purports to do. That is why our possession of everyday knowledge serves as the "soil" of closure's plausibility. Hence, $\mathrm{I} 1 *$ is ingrained in the paradoxical nature of the sceptical paradoxotherwise, there will be no paradox.

Now it should be obvious that if the sceptical paradox is to be genuinely paradoxical, I2 is not allowed to contradict I1 (more precisely speaking, I1*) - both claims have to be true. With these being said, the next question will be: is $\mathrm{I} 2 \mathrm{com}$ patible with I1? The answer is "no". It has been shown that I1* is a more accurate articulation of I1 and that the two claims should share the same truth value. I1* asserts that the closure principle is grounded in our widespread everyday knowledge, which means that the plausibility of the closure principle, qua an epistemic principle characterising the nature of our knowledge, is premised on the denial of the sceptical conclusion. I2 is thus shown to be in tension with I1. In summary, the tension between I1 and I 2 can be revealed by an argument as follows:

1. Our commitments to the plausibility of the closure principle are essential for the sceptical paradox. [From I1]

2. The sceptical conclusion is essential for the sceptical paradox. [From I2]

3 . The plausibility of the closure principle is grounded in our widespread everyday knowledge. [From I1*]

4. The sceptical conclusion denies that we possess everyday knowledge.

5. If the sceptical conclusion is true, then the closure principle will lose its ground of plausibility. [From 3, 4]

6. If the closure principle is well-grounded, then the sceptical conclusion is false. [From 3, 4]

Both 5 and 6 show that I1 and I2 are incompatible with each other. This indicates that the sceptical paradox is not a genuine paradox, because the sceptical paradox is premised on both I1 and I2. Without I1, we have no reason to see the closure principle as appealing; without I2, we have no reason to see our fundamental epistemological commitments as inconsistent. This dilemma reflects the self-hollowing problem of scepticism. The closure-based sceptical argument is typically self-hollowing. The sceptical conclusion makes its premise, i.e., the closure principle, become a hollow conditional and thus lose its foundation of plausibility. Sceptics have to choose from the hollowness of closure and the falsity of the sceptical conclusion-either choice would disarm the alleged sceptical paradox. 


\section{Objections and Rejoinders}

\subsection{Objection One}

Your solution turns essentially on the claim that the sceptical paradox requires I1 to be true. Sceptics may reject this claim. Why cannot the closure principle be considered part of our conception of knowledge? Perhaps closure simply expresses our (pre-theoretical) understanding of how knowledge can be acquired and transmitted. If so, then we do not have to consider the epistemic principle well-grounded in the way that you suggested in order to see it as a reasonable principle.

\subsection{Response}

The idea behind this objection is that closure's foundation of plausibility is not rooted in our possession of widespread everyday knowledge, but our "conception of knowledge". Closure matches and expresses our understanding of that conception ( $c f$. "a clairvoyant person can see the future" reflects our conception of clairvoyance, even though no one is clairvoyant). However, the problem of this objection lies in that it can hardly explain why closure matches our conception of knowledge and where this conception comes from.

The sceptical conclusion will make "everyday knowledge" an empty concept, i.e., a concept denoting no actual existing instances. Indeed, a statement can match the conception of an empty concept $\mathrm{C}$ and thus be plausible, if the statement involves an analytic truth concerning the definition of C. For example, the claim "a unicorn has a horn" just matches our conception of "unicorn" in this way. It is true in virtue of its meaning. However, as we have noted before, the closure principle is not an analytic truth concerning the meaning of "knowledge"-it is not deducted from the definition of knowledge. Thus closure cannot gain its plausibility in the same way that analytic truths do.

Another explanation for how closure matches our conception of knowledge can be that closure just expresses our reasonable imagination of knowledge. Even if there are no angels, the claim "angels' wings are white" still matches our reasonable imagination of angels' wings. Analogously, closure is a reflection of our fictional imagination of how knowledge extends and transmits. But again, this explanation fails to explain why this imagination is "reasonable" and thus fails to explain how closure can base its plausibility on such a fictional imagination.

More importantly, since our possession of actual knowledge is denied, it becomes unclear where our conception of knowledge comes from. Sceptics might reply that it comes from the orthodox epistemological narrations in the literature-but this does not touch the core of the query: in accordance with what does the orthodox epistemological literature depict the conception of knowledge like this, and still we find it plausible?

The most straightforward and convincing explanation is: "in accordance with our epistemic practices based on our widespread everyday knowledge". However, this explanation is denied by sceptics, while there is no competing explanation that is 
more plausible available for sceptics to advocate. Another potential sceptical explanation is that we deem closure valid in virtue of its successful applications to some non-empirical instances of knowledge (e.g., mathematical knowledge, known equivalence, conjunctive or disjunctive deductions), and thus we suppose that closure is also applicable to (empirical) quotidian propositions.

Nevertheless, this sceptical explanation is ad hoc and untenable. For one thing, here, the unrestricted validity of closure is assumed when it should be provedit is exactly the goal of this sceptical story to explain why closure can be valid in empirical domains as well as the non-empirical one. Hence this sceptical story fails to explain its real explanandum. For another thing, the motivation to credit closure with universal validity would be undermined by the intended sceptical conclusion, as if the sceptical argument succeeds, then closure's validity in the non-empirical domain cannot be transmitted to the empirical one. We just mistakenly take closure to be applicable in quotidian propositions - its plausibility is illusory.

The sceptical story is thus subject to a dilemma: on the one hand, it purports to explain how closure gains its plausibility; on another hand, it tells us that closure's plausibility is in fact illusory-this renders the sceptical explanation unconvincing and the sceptical argument untenable. This is not a difficulty exclusive for the "non-empirical to empirical" explanation, but a common defect for every sceptical explanation that reads closure as merely a part of our "conception of knowledge". In comparison, the traditional anti-sceptical narration is obviously more tenable. We take some epistemic exercises in our daily life to be successful—we name some of those epistemic successes as "knowing", from which we summarise an epistemic principle about how knowledge can be acquired or transmitted-the principle is named as "closure". That is how we ordinarily understand closure's foundation of plausibility.

So far, we have seen that sceptics cannot convincingly explain closure's foundation of plausibility in terms of our "conception of knowledge". But what if sceptics just bite the bullet and claim that closure is ill-grounded indeed?

Still, this objection fails to escape from the dilemma aforementioned. A sceptical paradox is premised on the plausibility of closure, which is undermined by scepticism as it explains closure's plausibility in an untenable way- "yes, closure is plausible, but it is taken to be plausible only for an implausible reason"- this explanation renders closure highly questionable. In addition, if closure is illgrounded indeed, then how can sceptics persuade us that closure is still plausible? To be more straightforward, how can sceptics persuade us that the closure principle is valid?

In any case, sceptics have to ensure the validity of closure, so that the closurebased sceptical argument can persist. The validity of closure used to be a consensus between sceptics and anti-sceptics, thus sceptics do not need to shoulder the extra burden of proof to prove it. Traditionally, we deem closure valid because it is wellgrounded in our widespread everyday knowledge. In short, it is I1* that constitutes the reason why we endorse closure's validity. That is the foundation of the aforesaid consensus. However, if it turns out that $\mathrm{I} 1 *$ is false, then the foundation is destructed, and the consensus is broken. The dialectical picture thereby alters-sceptics need us to endorse the closure principle, but they also reject the traditional reason for 
endorsing closure. Consequently, the onus is on sceptics to provide a correct reason as a replacement. In that case, closure, as a conditional, if still true, can only be trivially true. Surely, sceptics can claim that the intended sceptical conclusion can ensure closure to be true, as its antecedent can never be satisfied. However, this is just begging the question. Remember that the reason why sceptics have to prove closure to be trivially true is that they need closure to derive the sceptical conclusion. Sceptics cannot take what they ought to prove as the premise. Therefore, scepticism cannot survive by simply claiming that closure is ill-grounded.

\subsection{Objection Two}

The plausibility of closure is not grounded in our possession of everyday knowledge. Closure claims that knowledge is closed under known deduction, and deduction is a purely logical, non-empirical, and thus a priori operation. Hence the plausibility of closure is a priori. We do not need to possess actual everyday knowledge to find closure plausible. Rather, we just need to know what knowledge is and what logical deduction is, and then it will be a priori plausible that $q$ is known if we know that $p$ and that $p$ entails $q$.

\subsection{Response}

This objection puts forward a competing explanation for closure's plausibility, to wit, the "a priori account", which is closely connected to the aforementioned "analytic truth account" and "the conception of knowledge account". The objection suggests that by employing the a priori account, sceptics can avoid the self-hollowing problem. My reply is: this strategy cannot succeed, as the a priori account is not a good explanation for closure's plausibility that sceptics can rely on.

Firstly, there is no sufficient reason to see closure as a priori plausible. Closure is not a deductive logical principle, but an epistemic principle. The former is ordinarily a priori (e.g., the law of excluded middle), but the latter can be different. Despite the ambiguity of the concept "a priori", a typical a priori proposition usually expresses an analytic or necessary truth-roughly speaking, it is true by virtue of its meaning, ${ }^{14}$ e.g., "a bachelor is unmarried." However, as I have noted, closure does not involve any analytic truth regarding the definition of knowledge. That "everyday knowledge is closed" is not something that can be deduced logically from the definition of "everyday knowledge" (contra "a bachelor is unmarried"). Closure should better not be understood as analytically or necessarily true. Otherwise, it will be extremely odd why so many epistemologists argued against closure. The debate around the validity of closure at least shows that it is conceivable that knowledge is sometimes not closed. In contrast, it is difficult to conceive how a paradigmatic

\footnotetext{
${ }^{14}$ Admittedly, one can argue that the a priori/a posteriori distinction is different from the analytic/synthetic or the necessary/contingent distinction. The historic debate around the definition of "a priori" is far beyond what this paper purports to discuss. Traditionally, a negative definition of "a priori" is "be independent of any experience", while positive instances of a priori propositions pragmatically come in the form of analytic truths or necessary truths.
} 
a priori principle can be false (e.g., "if $\mathrm{A}$ is true and $\mathrm{B}$ is logically equivalent to $\mathrm{A}$, then B is true"). Thus, the a priori account is ill-motivated and ad hoc.

Secondly, the a priori account is a worse explanation for closure's plausibility compared with my explanation (which advocates I1*). Admittedly, there can be more than one proper explanation for closure's plausibility-I am not advocating an exclusive explanation. Here, the bone of contention is not what primarily makes closure plausible, but whether closure's plausibility can be properly justified without assuming that we have everyday knowledge. The sceptics say "yes", but I argue the opposite - that is the central divergence. Let me elaborate why the a priori account is defective in terms of this divergence.

An explanation for closure's plausibility is needed, because sceptics need to justify closure so that the sceptical argument can get off the ground. As we have noted before, the validity of closure is not as certain and clear as an analytic truth. There is even an ongoing debate around closure's validity in the literature. Two conflicting conceptions of knowledge are held by two sides of the debate regarding whether closure obtains. How can we determine which conception is correct? It is hard to accommodate such a dispute without resorting to instances of everyday knowledge (that we think we possess) in daily epistemic practices. Our conception of knowledge is expected to tally with our actual epistemic activities. Thus, when confronting the debate around closure, we investigate some cases based on our epistemic experiences (e.g., Dretske's "the zebra case") so that we can see which side of the debate coincides with our epistemic practices better. No matter to verify or to falsify the closure principle, one has to at least assume that we actually know something (e.g., "I see a zebra-like creature", "I am in a zoo") so as to ensure that the debate is not trivial. If that is the case, then one cannot justify closure without assuming our possession of actual knowledge. The a priori account thus fails to save scepticism.

What is worse, when attempting to explain closure's plausibility meanwhile rejecting to assume that we have everyday knowledge, one is virtually basing the plausibility of closure on a conception of knowledge that is independent of any actual extension. Hence the a priori account shares all defects of "the conception of knowledge account" that we discussed before. Both accounts endorse that to explain the plausibility of closure, we need to grasp the conception of knowledge. But where does our conception of knowledge come from provided that we have no knowledge? The a priori account does not go into this issue at all, leaving the essential explanandum unexplained. Our conception of knowledge - the alleged ground of closure's plausibility for the a priori account—seems to be ill-grounded if scepticism is true. That is, given the sceptical conclusion, "everyday knowledge" is an empty concept that has no actual extension. Our ordinary conception of knowledge is thus fallacious in the sense that we mistakenly see it as non-empty. Therefore, sceptics' explanation for closure's plausibility is oddly self-undermining: closure is grounded in our conception of knowledge, which is, however, fallacious and ill-grounded. It is thus hardly persuasive to justify closure's plausibility by the conception of knowledge without assuming our possession of everyday knowledge when the latter might also need to be justified. Moreover, the a priori account renders closure trivially 
true, which severely undermines the plausibility of closure qua an epistemic principle that we take to be widely applicable.

In summary, the a priori account is a bad explanation for closure's plausibility. It cannot save scepticism.

\subsection{Objection Three}

Why do we have to take the closure principle to be plausible? The mere validity of closure is sufficient for motivating the sceptical paradox. A paradox can just consist of a set of seemingly inconsistent yet true propositions, rather than plausible propositions.

\subsection{Response}

Firstly, the "plausibility-free" notion of paradox is questionable. It is obscure that a set of implausible but somehow true propositions can constitute a genuine paradox ( $c f$. Sainsbury's classic definition of "paradox"). Moreover, even if we put aside the disputes around how to define "paradox" and just presume that a paradox only needs its component propositions to be true, the sceptical paradox can still not be saved. That is because, as we have noted before, sceptics are still responsible for proving the closure principle to be valid. Given that they also need the sceptical conclusion to obtain, closure can only be trivially true. Sceptics can hardly prove closure to be trivially true in a non-circular manner.

\subsection{Objection Four}

Even though the well-grounded-ness of closure is incompatible with the truth of the sceptical conclusion, it is wrong that if closure is well-grounded, then there is no genuine paradox. According to Sainsbury's definition of "paradox", there is a paradox when an apparently unacceptable conclusion can be derived by apparently acceptable reasoning from apparently acceptable premises. The sceptical argument just presents us with a paradox that meets this definition. After all, the sceptical argument does not have to appear sound in order for there to be a paradox- the sceptical conclusion is unacceptable anyway.

\subsection{Response}

The sceptical paradox does not need the sceptical conclusion to be apparently true. However, it needs the sceptical conclusion to be derived in an apparently reasonable way. If sceptical argument's reasoning can be proved to be invalid or illegitimate, then the "apparent reasonableness" can be dispelled. There are at least two ways to see how the apparent reasonableness of the sceptical reasoning is dispelled:

Firstly, valid reasoning is truth-transmitting. An argument is valid iff the truth of its premises logically guarantees the truth of its conclusion. If the closure principle is well-grounded (in our widespread everyday knowledge), then it implies that the 
sceptical conclusion is not only unacceptable, but false. Without the analysis of scepticism's self-hollowing nature, we cannot conclude that the unacceptable sceptical conclusion is false straightforwardly when encountering the sceptical argument. Otherwise there would not have been the sceptical problem at all. However, after proving I1's contradiction with the sceptical conclusion, we are allowed to claim the sceptical conclusion to be false if closure is well-grounded. This transfers the sceptical argument from a seemingly paradoxical argument to an invalid argument-even if its premises are true, as long as closure is well-grounded, its conclusion would still be false.

Secondly, recall that the scope of closure's validity is subject to the truth value of the sceptical conclusion. If the sceptical conclusion is true, then the closure principle cannot be rightly applied to empirical knowledge, as we do not actually possess empirical knowledge. However, the sceptical argument employs closure by illegitimately applying it to the empirical domain in order to derive the sceptical conclusion. That means that the sceptical reasoning misjudges the scope of closure's validity and is thus a non sequitur.

\section{Theoretical Merits}

A new solution to the sceptical paradox has been given by revealing the self-hollowing problem of scepticism. In order to achieve this, the contradiction between I1 and I2 has been shown. Differing from traditional anti-sceptical strategies that refute $\mathrm{I} 1$ and $\mathrm{I} 2$ respectively, the solution proposed by this paper takes a third road. What contributions can this new solution make to current anti-sceptical discussions? Remember that in Sect. 2 we briefly listed the desiderata for an ideal anti-sceptical solution: being undercutting, being less theory-laden, and being widely applicable. The new solution satisfies them all.

Firstly, this new solution is an undercutting solution, which is preferable to an overriding one. An undercutting solution is characterised by its lower epistemologically cost, as it aims to prove the sceptical paradox to be pseudo, rather than admits the paradox as genuine and revises our fundamental epistemological commitments (like most anti-sceptical strategies that focus on rejecting I1 would be inclined to do). We have noted that a genuine sceptical paradox should be based on a wellgrounded closure principle. However, if closure is well-grounded, then we have to be in possession of widespread everyday knowledge so that closure is not hollow. This means that the closure-based sceptical argument, if spelled out, should be reformulated as follows:

[Well-Grounded Closure-based Sceptical Argument]

$(\mathrm{AC} 1 *)$ If I know everyday propositions and that everyday propositions entail that I am not a BIV, then I know that I am not a BIV. [Closure] $(\mathrm{AC} 2 *)$ I have widespread everyday knowledge. [Well-grounded-ness]

$\left(\mathrm{AC}^{*}\right.$ ) I do not know I am not a BIV. [Sceptical hypothesis]

$(\mathrm{AC} 4 *)$ I do not have any everyday knowledge. [Sceptical conclusion]

$\mathrm{AC} 2 *$ guarantees the closure principle to be well-grounded. Once AC2* is removed, due to the sceptical conclusion, closure would turn out to be hollow rather than 
well-grounded. However, AC2* also contradicts the sceptical conclusion straightforwardly. Accordingly, if the closure principle employed by sceptics is well-grounded, then the sceptical conclusion cannot be properly derived. The sceptical paradox will not occur. In any case, the alleged sceptical paradox cannot be a genuine paradox. The self-hollowing problem is thus undercutting.

Secondly, the new solution is not as theory-laden as most current mainstream anti-sceptical strategies. The way that we take to reveal the contradiction between I1 and 12 does not rely on any specific account of knowledge. It only utilises premises of the original sceptical argument that sceptics would also accept, plus some reasonable analyses of those premises. This should be seen as theoretical merit, as the new solution is not conditioned on any background theory's success, ${ }^{15}$ and hence has less burden of proof.

Thirdly, the self-hollowing problem applies to various versions of sceptical paradoxes. Most forms of sceptical paradoxes share the same template with the closurebased one. That is, a sceptical paradox typically consists of three claims:

1. A widely accepted epistemic principle (e.g., the closure principle, the underdetermination principle, etc.).

2. A sceptical hypothesis that violates the epistemic principle (e.g., "we do not know that we are not BIVs", "we do not have a better reason to believe that we are in a good case rather than a sceptical scenario", etc.).

3. We have widespread everyday knowledge.

The new solution proposed by this paper can serve as a unified solution, as any sceptical paradox fitting this template above will give rise to the self-hollowing problem. If the epistemic principle it employs is well-grounded, then the sceptical conclusion cannot be consistently derived; while if the epistemic principle turns out to be hollow, then it will lose its foundation of plausibility and hence the alleged paradox fails to be a genuine paradox.

Take another mainstream form of sceptical paradox, i.e., the underdeterminationbased sceptical paradox, as an example. It trades on the underdetermination principle, which requires us to have better reasons to believe that we are in epistemically good cases rather than sceptical scenarios, otherwise, we do not know everyday propositions. As with the closure principle, the plausibility of the underdetermination principle lies in its widespread successful applications in our daily epistemic practices. If it turns out that we do not have any everyday knowledge, then why are we required to have better reasons supporting our everyday beliefs? What can make the underdetermination principle valid? Moreover, if the underdetermination principle turns out to be hollow, uninformative and trivial, then why shall we deem it a fundamental epistemological commitment? A hollow underdetermination-based sceptical paradox is not the epistemologically interesting paradox that we have in mind. It should also not be what sceptics strive for. However, if it is granted that the underdetermination principle is not hollow but well-grounded and verifiable within the domain of everyday knowledge, then the sceptical conclusion would turn out to

\footnotetext{
15 Surely, this solution is still conditioned on the paradox reading of the sceptical problem, which should also be adopted by most competing anti-sceptical proposals.
} 
be false. Either way, the alleged underdetermination-based sceptical paradox cannot be genuinely paradoxical.

This solution also applies to other forms of sceptical paradoxes. ${ }^{16}$ Hence, contra what Pritchard (2015) suggests, we can put forward a unified solution to resolve different types of sceptical paradoxes. This constitutes the third advantage of my new solution.

\section{Concluding Remarks}

In this paper, I have provided a new solution to the sceptical paradox, which aims to reveal the self-hollowing problem of radical scepticism by showing the incompatibility between two essential claims supporting the paradoxical nature of the sceptical problem. The self-hollowing problem can be understood as a dilemma: on the one hand, if the epistemic principle that sceptics utilise to construct the sceptical argument is well-grounded, then the sceptical conclusion cannot be properly derived; on the other hand, if the essential epistemic principle turns out to be hollow, then it would lose its foundation of plausibility. In either case, the alleged sceptical paradox will become a pseudo-paradox regardless. This new solution has three theoretical merits: it is undercutting, less theory-laden and more widely applicable.

Acknowledgements I am grateful to anonymous reviewers for comments on earlier drafts of this paper. Special thanks to Duncan Pritchard, Martin Smith, and J. Adam Carter for their patient guidance and helpful discussions about this article. In addition, thanks to Yijie Shen, and audiences at the University of Edinburgh and the 24th World Congress of Philosophy, for their valuable feedback. This work was funded by China Scholarship Council.

Open Access This article is distributed under the terms of the Creative Commons Attribution 4.0 International License (http://creativecommons.org/licenses/by/4.0/), which permits unrestricted use, distribution, and reproduction in any medium, provided you give appropriate credit to the original author(s) and the source, provide a link to the Creative Commons license, and indicate if changes were made.

\section{References}

Ashton, N. A. (2015). Undercutting underdetermination-based scepticism. Theoria, 81(4), 333-354.

Atkins, P., \& Nance, I. (2014). A problem for the closure argument. International Journal for the Study of Skepticism, 4(1), 36-49.

Baumann, P. (2017). Review of 'The illusion of doubt' by G. Schönbaumsfeld. Notre Dame Philosophical Reviews. http://works.swarthmore.edu/fac-philosophy/532. Accessed 20 Nov 2017.

Bernecker, S. (2012). Sensitivity, safety, and closure. Acta Analytica, 27(4), 367-381.

Brueckner, A. (1994). The structure of the skeptical argument. Philosophy and Phenomenological Research, 54, 827-835.

\footnotetext{
16 For example, Schaffer's debasing scepticism, which trades on the so-called basing condition of knowledge to motivate the sceptical argument (see Schaffer 2010). Also, the sensitivity-based scepticism and the KK-based scepticism (the former utilises the well-known sensitivity principle and the latter employs the KK principle). They are all subject to the self-hollowing problem, as the plausibility of the basing condition, sensitivity and KK are all based on our possession of everyday knowledge.
} 
Brueckner, A. (2005). Fallibilism, underdetermination, and skepticism. Philosophy and Phenomenological Research, 71(2), 384-391.

Byrne, A. (2004). How hard are the sceptical paradoxes? Noûs, 38(2), 299-325.

Cohen, S. (1998). Contextualist solutions to epistemological problems: Scepticism, Gettier, and the lottery. Australasian Journal of Philosophy, 76, 289-306.

Coliva, A. (2015). Extended rationality: A hinge epistemology. Basingstoke: Palgrave-Macmillan.

DeRose, K. (1995). Solving the skeptical problem. The Philosophical Review, 104(1), 1-52.

DeRose, K. (1999). Contextualism: An explanation and defense. In J. Greco \& E. Sosa (Eds.), The Blackwell guide to epistemology (pp. 185-203). Oxford: Blackwell.

Dretske, F. (1970). Epistemic operators. Journal of Philosophy, 67(24), 1007-1023.

Dretske, F. (1981). Knowledge and the flow of information. Cambridge: MIT Press.

Dretske, F. (2005). The case against closure. In M. Steup \& E. Sosa (Eds.), Contemporary debates in epistemology (pp. 13-26). Oxford: Blackwell.

Engel, M., Jr. (2004). What's wrong with contextualism, and a noncontextualist resolution of the skeptical paradox. Erkenntnis, 61(2-3), 203-231.

Floridi, L. (2014). Information closure and the sceptical objection. Synthese, 191(6), 1037-1050.

Goldman, A. I. (1976). Discrimination and perceptual knowledge. Journal of Philosophy, 73, 771-791.

Greco, J. (2002). Virtues in epistemology. In P. Moser (Ed.), Oxford handbook of epistemology (pp. 287315). New York: Oxford University Press.

Hawthorne, J. (2004). Knowledge and lotteries. Oxford: Oxford University Press.

Hetherington, S. (2001). Good knowledge, bad knowledge: On two dogmas of epistemology. Oxford: Oxford University Press.

Huemer, M. (2001). Skepticism and the veil of perception. Lanham: Rowman \& Littlefield.

Klein, P. (2004). Closure matters: Academic skepticism and easy knowledge. Philosophical Issues, 14, $165-184$.

Kvanvig, J. (2006). Closure principles. Philosophy Compass, 1(3), 256-267.

Nozick, R. (1981). Philosophical explanations. Cambridge: Harvard University Press.

Pritchard, D. (2005a). Epistemic luck. Oxford: Oxford University Press.

Pritchard, D. (2005b). The structure of sceptical arguments. The Philosophical Quarterly, 55(218), 37-52.

Pritchard, D. (2007). Anti-luck epistemology. Synthese, 158, 277-298.

Pritchard, D. (2009). Scepticism and the possibility of knowledge. Analysis, 69, 317-325.

Pritchard, D. (2015). Epistemic angst: Radical scepticism and the groundlessness of our believing. Princeton: Princeton University Press.

Pritchard, D. (2016). Epistemic angst. Philosophy and Phenomenological Research, 93(3), 533.

Sainsbury, R. (2009). Paradoxes. Cambridge: Cambridge University Press.

Schaffer, J. (2010). The debasing demon. Analysis, 70(2), 228-237.

Schiffer, S. (1996). Contextualist solutions to skepticism. Proceedings of the Aristotelian Society, 96, 317-333.

Schiffer, S. (2004). Skepticism and the vagaries of justified belief. Philosophical Studies, 103, 161-184.

Schönbaumsfeld, G. (2016). The illusion of doubt. Oxford: Oxford University Press.

Sosa, E. (1999). How to defeat opposition to Moore. Philosophical Perspectives, 13, 141-154.

Stroud, B. (1984). The significance of philosophical scepticism. Oxford: Clarendon Press.

Williams, M. (1996). Unnatural doubts: Epistemological realism and the basis of scepticism. Princeton: Princeton University Press.

Williamson, T. (2000). Knowledge and its limits. Oxford: Oxford University Press.

Wong, W. (2005). The skeptical paradox and the indispensability of knowledge-beliefs. Synthese, 143(3), 273-290.

Wright, C. (2008). Internal-external: Doxastic norms and the defusing of skeptical paradox. Journal of Philosophy, 105(9), 501-517. 